\title{
Marine-Related Learning Networks: Shifting the Paradigm Toward Collaborative Ocean Governance
}

\section{OPEN ACCESS}

Edited by:

Gretta Pecl,

Centre for Marine Socioecology, Australia

Reviewed by:

Tim Gray,

Newcastle University, United Kingdom Jessica N. Cross,

Pacific Marine Environmental Laboratory (NOAA), United States

*Correspondence: Kathryn Dalton kdalton@uw.edu Marlena Skrobe mskrobe@uw.edu

Henry Bell

habel/@uw.edu

${ }^{\dagger}$ These authors have contributed equally to this work

Specialty section:

This article was submitted to Ocean Solutions,

a section of the journal

Frontiers in Marine Science

Received: 15 August 2020 Accepted: 19 October 2020 Published: 09 November 2020

Citation:

Dalton K, Skrobe M, Bell H,

Kantner B, Berndtson $D$, Gerhardinger $L C$ and Christie $P$ (2020) Marine-Related Learning Networks: Shifting the Paradigm

Toward Collaborative Ocean Governance.

Front. Mar. Sci. 7:595054. doi: 10.3389/fmars.2020.595054

\author{
Kathryn Dalton ${ }^{1 * t}$, Marlena Skrobe ${ }^{1,2 * t}$, Henry Bell ${ }^{* *}$, Benjamin Kantner ${ }^{3}$, \\ Dave Berndtson ${ }^{1,4}$, Leopoldo C. Gerhardinger ${ }^{5}$ and Patrick Christie ${ }^{3}$
}

${ }^{1}$ School of Marine and Environmental Affairs, University of Washington, Seattle, WA, United States, ${ }^{2}$ Nippon Foundation Ocean Nexus Center, Earthlab, University of Washington, Seattle, WA, United States, ${ }^{3}$ School of Marine and Environmental Affairs and Henry M. Jackson School of International Studies, University of Washington, Seattle, WA, United States, ${ }^{4}$ Gulf of Maine Research Institute, Portland, ME, United States, ${ }^{5}$ Brazilian Future Ocean Panel, Brasilia, Brazil

Formal and semi-formal networks are emerging as effective, collaborative, and adaptable approaches for addressing complex, rapidly evolving ocean governance issues. One such group of networks, which we refer to as marine-related learning networks, play multifaceted roles within ocean governance systems by facilitating knowledge creation, exchange, and dissemination, and by building the capacity of individuals and institutions to address problems and improve coastal and ocean governance. This study investigates the emergence, key attributes, and outcomes of marine-related networks using semi-structured interview data from 40 key informants representing 16 different networks that operate around the world at local, national, regional, and global scales. Our findings indicate that marine-related learning networks form in response to knowledge and action gaps and the specific needs of network members, and they function to inform policy and improve ocean management. Their success depends on attributes such as having a distinct purpose, building trust and relationships, emphasizing equitable participation, and supporting clear, sustained leadership. Marine-related learning networks are uniquely positioned to act as catalyzers and conduits to build capacity and develop solutions in response to governance needs through inclusive and collaborative responses to ongoing and emerging marine issues. As such, a broader understanding of their growing significance and the effective practices they employ is warranted.

Keywords: knowledge networks, knowledge exchange, ocean governance, capacity building, communities of practice, marine management, collaboration, learning networks

\section{INTRODUCTION}

The decline in global ocean health is a serious threat to all aspects of human well-being and livelihoods (Bindoff et al., 2019) and the inefficiencies of long-standing ocean governance structures and attempts to transform them are widely recognized (Kelly et al., 2018). These structures are limited by a lack of stakeholder inclusion and are bound by geography and politics (Crowder et al., 2006; Rosen and Olsson, 2013). In traditional coastal and ocean governance systems, there are mismatches between the concepts, instruments, and actions for addressing problems; responsiveness to ever-evolving issues is often insufficient; and asymmetric power distribution 
amongst concerned actors leads to underperformance in longterm capacity building for problem solving (Chuenpagdee and Jentoft, 2013; Maxwell et al., 2015; Gill et al., 2017). Too often, they rely on one-size-fits-all management prescriptions and top-down, mono-disciplinary governance approaches, which fall short in addressing complex, transboundary ocean issues (Ostrom, 2007).

Achieving ambitious large-scale goals, like the UN Sustainable Development Goals (SDGs), will only be possible in the ocean realm if the status quo approach to governance and management evolves to focus on equity, collaboration, and adaptability (Cisneros-Montemayor et al., 2019). In addition, the centering of affected communities and their participation from the early stages of planning and decision making is vital for effective conservation and management of marine areas (Pomeroy and Douvere, 2008; Cárcamo et al., 2014). The concepts of networks and network structures, which embrace these critical and inclusive approaches, are at the forefront of innovative solutions for the complex problems facing our oceans and the livelihoods of those who depend on them (Keast et al., 2004).

\section{Learning and Knowledge Networks}

In its most simplistic form, a network is a set of actors or nodes that are linked through a specific social or communication tie (Borgatti and Halgin, 2011). Networks are utilized across many fields and disciplines, can be formal or informal, and cover a diverse array of objectives and purposes that have been recognized as a critical form of multi-organizational governance (Provan and Kenis, 2008). They can incorporate actors from a single discipline, multiple disciplines, or they may practice a transdisciplinary approach, leveraging multiple kinds of expertise in order to develop a more holistic understanding of a topic (Apostel, 1972; Rosenfield, 1992; Klein, 2008).

Networks that bring individuals together with mutual concerns to increase their shared knowledge by learning from one another are commonly referred to as "learning networks" or "knowledge networks" (Creech and Willard, 2001; The Heinz Center, 2004). Rather than impose fixed solutions, such networks utilize an iterative process of learning and knowledge exchange over long periods of time, with learning taking place at both the individual and group level (Berkes, 2008, 2009; De Kraker et al., 2013). Learning and knowledge networks can be molded into a wide variety of means to construct and disseminate knowledge, with certain networks exhibiting more horizontal, hierarchic or cross-scale dynamics. But in many cases, these networks emphasize horizontal, transformative work of participants (McFarlane, 2009; Tschirhart et al., 2016). There are also many other terms used to describe networks comprised of individuals, communities, or organizations who come together to share and create knowledge and learn by practice (Pietri et al., 2015), including communities of practice (Wenger et al., 2002), social networks (Walton et al., 2014), epistemic communities (Adler and Haas, 1992), and knowledgeaction networks (Shrivastava et al., 2016).

Because of their inclusive and responsive emphasis on knowledge creation, knowledge transmission, and participatory action (Tobey and Volk, 2002; Matous and Todo, 2015), some of these networks are poised to provide efficient and innovative means of addressing the fundamental challenges of oceanrelated "wicked problems" (Weber and Khademian, 2008). These problems are relentless, indeterminate, and ever-evolving (Rittel and Webber, 1973; Weber and Khademian, 2008). They have multiple explanations, no single solution, and they cross-cut other problems, societal sectors, and policy domains (Ackoff, 1974; Clarke and Stewart, 1997). As such, the dynamic and continual flow of information and good practices within learning networks may foster adaptive and proactive approaches necessary to address these wicked problems associated with ongoing ocean governance challenges (Cvitanovic et al., 2015).

In this paper, we examine a collection of learning and knowledge networks that address marine issues and aim to benefit societies that depend on ocean resources, which we collectively refer to as "marine-related learning networks." Our goal is to distill the critical traits of marine-related learning networks by outlining why they emerge and develop, describing the conditions and approaches we found to be key enabling factors for network success, and discussing the roles they play in ocean governance. While previous studies have examined these topics in relation to specific networks, none have integrated findings across a diversity of networks. We seek to narrow that knowledge gap with a broad, qualitative study of marine-related learning networks. Three primary questions guided the research process: (1) What are marine-related learning networks and why do they form? (2) What are the outcomes of marine-related learning networks and how do they achieve them? (3) What attributes are most essential to the success of marine-related learning networks?

\section{MATERIALS AND METHODS}

To understand the role of marine-related learning networks in global ocean governance, we conducted qualitative, semistructured interviews with 40 key informants in 16 different marine-related learning networks (Table 1). Our sample included a diverse representation of marine-related learning networks that operate at local, national, regional, and global scales across the world. The selected networks vary widely; in their duration of existence, goals they pursue, and actors they involve. Between 1 and 7 informants were interviewed from each network. Of the 40 informants, 6 represented local networks, 4 represented national networks, 13 represented regional networks, and 17 represented global networks. These key informants were located in 13 countries, and all worked as either a leader $(n=8)$, coordinator $(n=12)$, advisor $(n=15)$, or core staff member $(n=5)$. Informants ranged in experience from early career to retired professionals. All interviews were conducted and transcribed between November 2019 and January 2020.

This was an Ad hoc study conducted to foster a nascent Brazilian marine-related learning network, the Brazilian Future Ocean Panel (PainelMar) ${ }^{1}$. Interview questions were developed

\footnotetext{
${ }^{1}$ https://painelmar.com.br/
} 
TABLE 1 | The 16 networks included in our study, as well as the scales and locations in which they operate and the year each network was established.

\begin{tabular}{|c|c|c|c|}
\hline Network & Scale & Location & Year established \\
\hline Big Ocean Network & Global & Global & 2010 \\
\hline Brazilian Future Ocean Panel (PainelMar) ${ }^{a}$ & National & Brazil & 2015 \\
\hline Caribbean Marine Protected Area Management Network and Forum (CaMPAM) & Regional & Caribbean & 1997 \\
\hline Coral Triangle Initiative on Coral Reefs, Fisheries, and Food Security (CTI-CFF) & Regional & Western Pacific & 2009 \\
\hline Earth Systems Governance Project (ESG) ${ }^{b}$ & Global & Global & 2008 \\
\hline Future Earth Ocean Knowledge-Action Network (Future Earth Ocean KAN)c & Global & Global & 2012 \\
\hline Global Socioeconomic Monitoring Initiative for Coastal Management (SocMon) ${ }^{c}$ & Global & Global & 2002 \\
\hline Madagascar Locally Managed Marine Area Network (MIHARI) ${ }^{d}$ & National & Indian Ocean & 2012 \\
\hline Mediterranean Protected Area Network (MedPAN) & Regional & Mediterranean & 1990 \\
\hline Mesoamerican Reef Fund (MAR Fund)e & Regional & Caribbean & 2004 \\
\hline MPAConnect & Regional & Caribbean & 2010 \\
\hline Pacific Islands Marine Protected Area Community (PIMPAC) & Regional & Western Pacific & 2005 \\
\hline Pohnpei Teachers' Learning Community (PTLC) climate-related knowledge network & Local (regionally affiliated) & Micronesia & 2016 \\
\hline Reef Resilience Network (RRN) & Global & Global & 2005 \\
\hline SMART Seas Africa Programme (SMART Seas) & Regional & Indian Ocean & 2009 \\
\hline Too Big To Ignore (TBTI) & Global & Global & 2012 \\
\hline
\end{tabular}

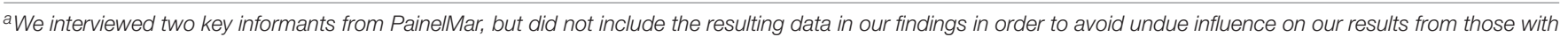
whom we collaborated to determine our project scope and research questions.

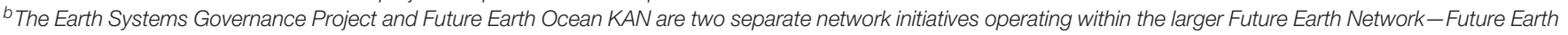
is often referred to as a "network of networks" (Informant interviews, 2019-2020).

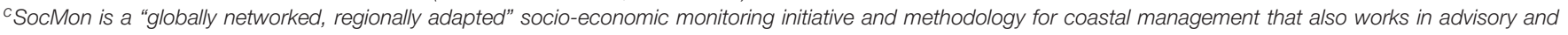
ancillary capacities with other networks (SocMon, 2020).

"MIHARI is an acronym for MItantana HArena Ranomasina avy eny Ifotony, which roughly translates to "marine resource management at the local level" (MIHARl, 2020).

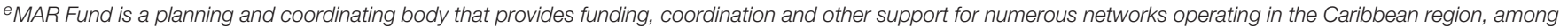
other activities.

in collaboration with experts from PainelMar. The authors maintained active communication with PainelMar leadership to ensure that our research reflected the realities of marine-related learning networks.

A grounded theory approach was used during interviewing and data analysis in order to avoid bias and engage in an iterative and inductive process that allowed novel ideas to emerge (Glaser and Strauss, 1967). Questions were adapted throughout the interviewing process to explore new themes and reduce manipulation of research findings, in accordance with the principles of Naturalistic Inquiry (Lincoln and Guba, 1985). Interviews were coded using the principle of theoretical sensitivity and the processes of open and axial coding (Strauss and Corbin, 1990). All analyses were performed using Atlas.ti software version 8 and Atlas.ti Cloud. 25 code categories were created based on five core interview question themes: (1) Rationale, (2) Operations, (3) Leadership, (4) Participation, and (5) Activities and Outcomes. A sixth auxiliary theme was used to illuminate challenges, lessons learned, and external influences within each of the five core themes. Initial coding was conducted in two rounds. The first round followed the principles of open coding and was conducted by a member of the research team who had not participated in the interview, in order to apply a fresh perspective to the informant's answers. The second round of coding was conducted by a researcher who had participated in the interview in order to correct for any information within the answers that had been misinterpreted or missed. Based on these first two rounds of coding and our interactions with the data, we adjusted our code categories and their dimensions for the next step of our analysis. Each researcher was then assigned to one of these code categories to conduct axial coding, the descriptive breakdown of core themes in order to allow the reshaping and emergence of conceptual themes. During this theory development process, we used inference and deductive reasoning to elucidate relationships between categories and concepts, identifying and synthesizing the most salient portions of our data (Strauss and Corbin, 1990).

\section{RESULTS AND DISCUSSION}

\section{The Need for Marine-Related Learning Networks}

The marine-related learning networks in our study are united in their purpose of increasing the knowledge and capacity of network members. This is reflected in the basic foundation of a learning network, whose core function is to increase knowledge through information sharing and collaborative knowledge development (Bessant and Tsekouras, 2001). One informant described a learning network as a "loose organization of people all working towards similar goals that have opportunities to learn from each other." While the formality, organizational structure, scale, and timeline of each network varies, marinerelated learning networks work toward these goals by connecting individuals who benefit from learning and working together rather than working separately. In many cases, these networks mobilize knowledge in order to inform and influence policy or assist communities in taking collective action. 
While the marine-related networks in our study share numerous characteristics, our informant interviews demonstrate that there is no clear ontology or one set way to define marinerelated networks designed for the purpose of learning and/or knowledge exchange (Figure 1). The differences in terminology used can be attributed to a network's cultural and linguistic context, the needs and organization of the network, who is involved in the network, and what the overall goals of the network are (Poell et al., 2000). This flexibility in terminology was highlighted by informants in our study as an integral part of the adaptability of network definitions, which are reflective of the dynamic structures, sizes, and actors involved in the network. As noted by a leader of a global network, "The terminology just matters to whatever person you're trying to talk to...I need to keep trying new words until I get that they understand what we're doing." Having flexibility with network definitions leads to an improved mutual understanding of what the network is trying to achieve, an important consideration in an emerging field.

The impetus behind the emergence of these marine-related learning networks springs from the nature of ocean management and governance challenges: they are complex and constantly changing, they transcend governance boundaries, and those taking action to address them require urgent access to resources and information (Scarlett and McKinney, 2016). Addressing these challenges is a knowledge-intensive endeavor that evolves over time. An informant from MPAConnect described how the network allows for an iterative process of learning to take place: "[The network] acts as a bridge for them to connect with each other, to connect with technical experts, and to help them seek information, knowledge, best practices, or whatever they might need." With regard to knowledge, many networks in our study developed because necessary resources and information, such as technical expertise, were available, but not in the hands of practitioners and other actors closest to the issues. This disconnect can take place at various scales across one or many foci. An informant from the PTLC climate network further elaborated on this point by explaining how local teachers did not have the resources they needed to teach about how climate change was directly impacting their community:

"There was a disconnect between the resources that were available locally and the teachers that wanted that sort of information. We didn't go into this thinking it would be a knowledge network or a learning network. It just evolved based on the needs that were there."

In this particular case, the network served as a venue for members of the same community to connect and share available knowledge.

In other instances, established and nascent marinerelated issue-areas mobilized researchers, practitioners, and stakeholders to come together to develop and/or "co-produce" new knowledge to build a more holistic understanding of an issue (Armitage et al., 2012).

The need to increase information-sharing and build local capacity was also commonly referenced by our informants. Many networks in our study, especially national and local networks, are set up to empower communities to tackle local and timely issues. In contrast, prioritization of outside interventions and leadership can often be expensive and inefficient, privilege Western organizational processes, or insufficiently incorporate local perspectives (Scarf and Hutchinson, 2003). An informant stressed the importance of learning and building capacity within local communities as a way to reduce reliance on expensive outside support structures and encourage community resilience:

"This is an area where there's very little resources. We have to be very careful with our resources. We can't be paying for $\$ 800$ a-day scientists to come and help every other individual site or community. By doing this learning network, we've cut down so

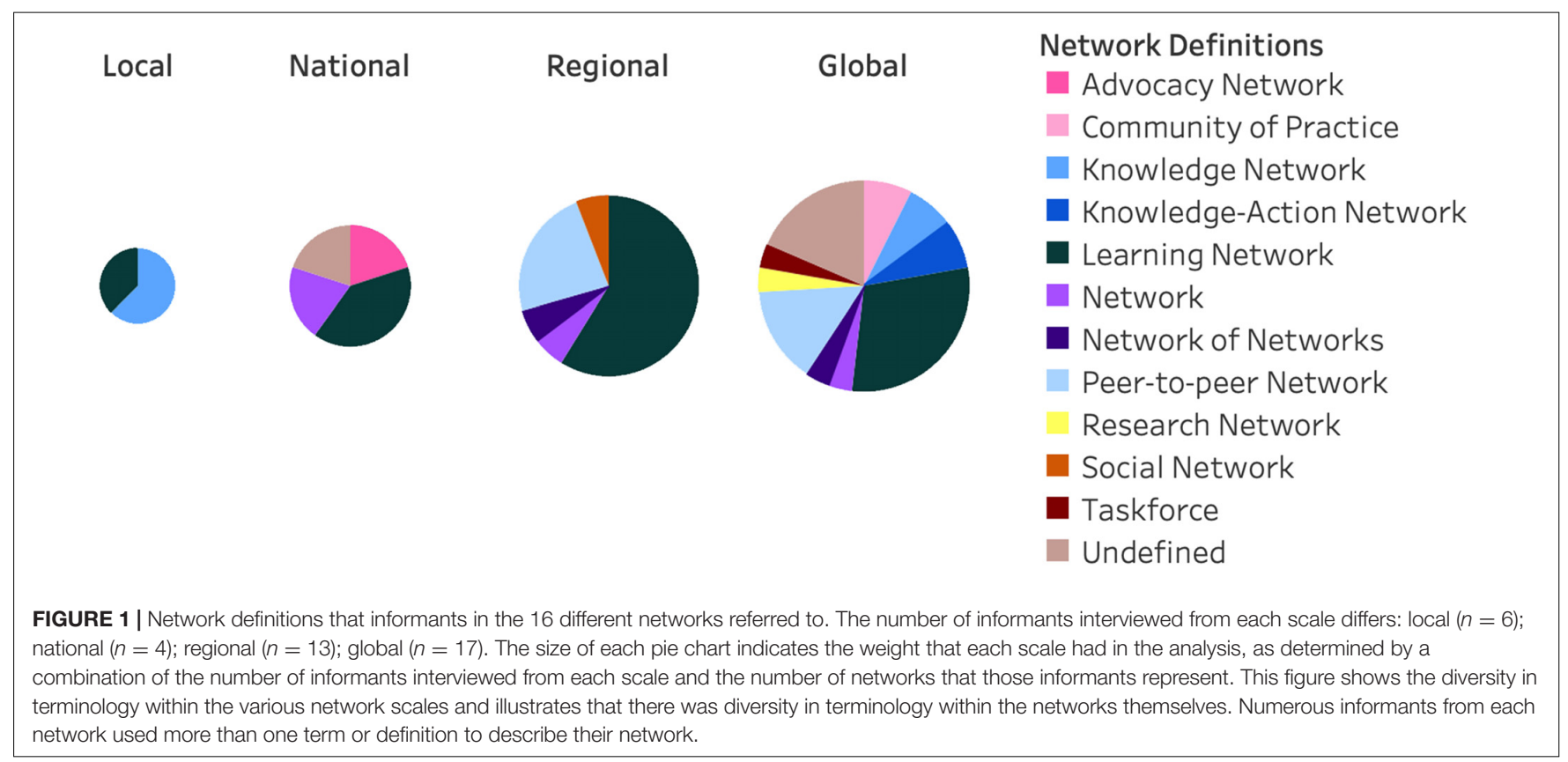


much on those expenses [by] having members be able to help each other out...So weve reduced a lot of the costs to conservation in Micronesia by building the expertise within our own learning network."

While learning networks give priority to learning and capacity development through participatory goals and activities, they may still fall into the same problems as long standing traditional governance structures that limit local participation and empowerment (Scarf and Hutchinson, 2003).

While local environmental issues demand localized stewardship, an increasing number of environmental problems cross political boundaries or are shared by many different countries, necessitating shared learning and regular exchanges of best practices at larger scales (Mitchell, 2010). Therefore, many of the global and regional marine-related learning networks in our study connect individuals in order to tackle transboundary ocean challenges. For example, an informant from CTI-CFF, located in the Coral Triangle, described the need for collaboration between countries in the Coral Triangle region:

\footnotetext{
"To be effective in this region, countries need to work together because there's a lot of cross-boundary issues. Fisheries are not limited to one country. There are pollution issues, lots of migrant fishermen, illegal activities going on, and all sorts of things that involve these countries. Not to mention that they are the center of marine biodiversity in the world. So, they have a lot of common interests."
}

These networks provide a space where individuals or organizations from various countries can collaborate and work to address shared challenges.

In addition to coming together to tackle shared problems, networks provide a space where members can share lessons learned, successes, and even failures from one country to another. One informant from PIMPAC remarked on how working in the field of marine conservation can be isolating and difficult as failure is frequent, and the network has been instrumental in helping participants navigate those challenges and stay motivated:

\begin{abstract}
"Our field can be lonely sometimes...You're working hard on something and then a development comes in and almost erases everything that you're trying to do. So, these learning networks really provide that support that you need. When you get bogged down or you get challenged, you get tired, they really provide energy. Every time we have a PIMPAC workshop or a PIMPAC get together, it just reenergizes you, that there are people out there that are having the same challenges that you have, that are struggling along those same lines. And it's always good to share with people who understand where you're coming from. And also when you see success in other areas that you're struggling in, then it gives you new hope and new ideas for doing better."
\end{abstract}

This sentiment was echoed by numerous informants who described the need for a support system in the face of challenging conservation and ocean management work. Having a venue where lessons learned from both successes and failures allows for the development of trust and deeper learning among network members (Ostrom et al., 1999). This support system reinvigorates network participants and, in many cases, allows for a diverse array of actors and stakeholders who would not otherwise have an opportunity to learn from one another to come together over shared commonalities.

\section{The Activities and Outcomes of Marine-Related Learning Networks Activities and Functions}

Depending on their goals and objectives, marine-related learning networks perform a broad variety of functions, collaborating and engaging with a variety of actors across local, national, regional, and international scales. Many networks aim to generate on-the-ground improvements in marine management by conducting capacity building workshops, skill development sessions, and peer-to-peer learning exchanges. Marine-related learning networks also bring together diverse stakeholders at meetings and forums, engage with scientists, decision makers, and other actors at international conferences, and coordinate ongoing data collection initiatives in order to inform the development and implementation of effective policies, such as sustainable fisheries regulations or new marine protection measures. Furthermore, they assist in the creation of products with applied uses, such as protected area guidelines or coral restoration guidebooks, and contribute toward influential scientific publications and informational databases.

There is no formally established method for categorizing or defining the wide variety of marine-related learning networks that exist. However, Table 2 presents an overview of common held activities, outputs, and intended outcomes of four generalized categories of marine-related learning networks based on patterns that emerged within our analysis. The categories are not intended to imply a clear typology; many of the networks involved in this study exhibit elements of multiple categories. Rather, the groupings are arranged to assist in understanding all that marine-related learning networks do.

In Table 2, knowledge sharing networks refer to networks that primarily intend to connect their participants or partners with access to information relevant to their research, their jobs, or other aspects of their livelihoods. They are typically transdisciplinary and multi-sectoral and can emphasize and utilize information sharing, peer-learning, and/or knowledge dissemination methods. Capacity building and empowerment may not be explicitly held goals of these networks but may result from their activities. Advisory-focused networks refer to networks that intend to influence or inform policy and ocean governance at national, regional, or international levels. They also emphasize or contain aspects of knowledge sharing networks. MPA-focused networks refer to networks that work primarily with marine protected area managers and staff with the intent of building management capacities and improving the effectiveness of marine protected areas. They also emphasize or contain aspects of knowledge sharing networks. Hybrid networks refer to networks that encompass key elements of all three aforementioned network categories. They emphasize knowledge sharing, they work with diverse partners and sectors of society, they will aim to inform and influence policy, and they work with officials to improve the management of marine areas. 
TABLE 2 | Four generalized marine-related learning network categories and their associated activities, outputs, and intended outcomes.

\begin{tabular}{|c|c|c|c|}
\hline $\begin{array}{l}\text { Marine-related } \\
\text { network category }\end{array}$ & Formal activities & Products and outputs & Intended outcomes \\
\hline $\begin{array}{l}\text { Knowledge sharing } \\
\text { networks }\end{array}$ & $\begin{array}{l}\text { - Informational workshops, trainings and } \\
\text { meetings } \\
\text { - Collaborative scholarship }\end{array}$ & $\begin{array}{l}\text { - Informational databases } \\
\text { - Research/informational reports } \\
\text { - Peer-reviewed publications }\end{array}$ & $\begin{array}{l}\text { - Connect science, society and policy } \\
\text { - Empower coastal communities } \\
\text { - Improve access to information and } \\
\text { communication between coastal communities } \\
\text { for a wide variety of purposes }\end{array}$ \\
\hline $\begin{array}{l}\text { Advisory-focused } \\
\text { networks }\end{array}$ & $\begin{array}{l}\text { - Host or participate in large multi-sectoral } \\
\text { meetings and conferences } \\
\text { - Collaborative scholarship }\end{array}$ & $\begin{array}{l}\text { - Peer-reviewed publications } \\
\text { - Policy briefs } \\
\text { - Guideline documents }\end{array}$ & $\begin{array}{l}\text { - Connect science, society, and policy } \\
\text { - Incorporate multiple perspectives in policy } \\
\text { processes } \\
\text { - Influence, shape, or advocate for ocean and } \\
\text { coastal policies }\end{array}$ \\
\hline $\begin{array}{l}\text { Marine Protected Area } \\
\text { (MPA)-focused networks }\end{array}$ & $\begin{array}{l}\text { - Capacity building workshops } \\
\text { - Management trainings } \\
\text { - Learning exchanges } \\
\text { - Data collection assistance } \\
\text { - Management monitoring }\end{array}$ & $\begin{array}{l}\text { - Management guidebooks } \\
\text { - Online training resources } \\
\text { - Informational databases }\end{array}$ & $\begin{array}{l}\text { - Improve MPA management capacities, expand } \\
\text { approaches employed and perspectives used } \\
\text { - Improve effectiveness of MPAs } \\
\text { - Improve marine ecosystem health }\end{array}$ \\
\hline Hybrid networks & $\begin{array}{l}\text { - Capacity building workshops } \\
\text { - Management trainings } \\
\text { - Learning exchanges } \\
\text { - Host or participate in large multi-sectoral } \\
\text { - } \text { meetings and conferences } \\
\text { - Deadership development programs } \\
\text { - Management monitoring } \\
\text { - Collaborative scholarship }\end{array}$ & $\begin{array}{l}\text { - Online training resources } \\
\text { - Informational databases } \\
\text { - Peer-reviewed publications } \\
\text { - Policy briefs } \\
\text { - Research/informational reports }\end{array}$ & $\begin{array}{l}\text { - Connect science, society and policy } \\
\text { - Influence, shape, or advocate for ocean and } \\
\text { coastal policies } \\
\text { - Empower coastal communities } \\
\text { - Leadership development } \\
\text { - Improve MPA management capacity, MPA } \\
\text { effectiveness, and ecosystem health }\end{array}$ \\
\hline
\end{tabular}

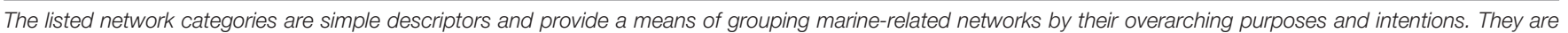

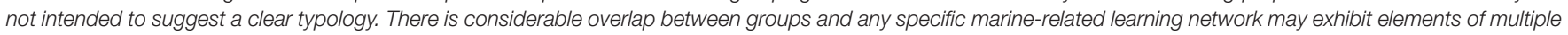
categories.

Empowerment and capacity building are also common goals of hybrid networks. In many cases, these networks are able to employ a wider range of approaches and pursue multiple goals because they have access to more resources and funding.

\section{Outcomes and Impacts}

Most marine-related learning networks in our study aim to support healthy marine environments and improve the lives of those who depend on ocean resources. Directly linking a network's activities to positive ecological outcomes is a challenge that many networks have in common, as quantifying potential indirect impacts of network activities is exceedingly difficult. Despite this challenge, our informants shared numerous stories of success, on-the-ground improvements in management, and cases where network activities influenced and informed good policy which suggest that networks often play integral roles in benefiting both society and marine environments. Speaking about governance outcomes that have resulted from their work, an informant from PIMPAC said, "We identified about twenty different policies, for example fisheries regulations, that have been implemented because we had science to show policymakers [what they should do]." The informant provided several examples of particular policies and recalls a conversation with one of their network's lead advisors: "He agreed, these regulations wouldn't have happened if we weren't collecting this data, analyzing $i t$, managing it, and then leveraging additional funds from private organizations... to provide additional training for effectively communicating science to policymaker."
Marine-related learning networks can also help support resolutions for social and environmental problems by representing local community interests and convening meetings and other events that bring together diverse cohorts of decision makers and stakeholders. An informant from MIHARI described how they organized three workshops at both regional and national scales in Madagascar to discuss illegal fishing of undersized mangrove crabs:

"[MIHARI and their partners were able] to get people together from the ministry, from the committees, from NGOs, [and] the private sector, to come up with solutions in order to support the communities so they can still fish, but also to preserve the environment and the species. It was a lot of discussions and at the end, the ministry agreed, and one result out of it was to implement a [temporary] national closure."

While many networks regularly convene various stakeholder groups to elicit collaborative solution making, the most pervasive strategy across networks for generating successful governance outcomes is through capacity building activities of those in management or policymaking positions. Capacity building refers to specialized education, training, or other processes that enhance the skills and problem solving capabilities of people and institutions (Cicin-Sain and Knecht, 1998; Fukuda-Parr et al., 2002). It is generally not achievable through standard university-style courses or other conventional education programs (Wescott, 2002). Developing capacity within the communities in which networks exist is often a critical priority, 
especially since reliance on distant external assistance is often costly, insufficient, or ineffective.

Informants routinely expressed that information exchanges and capacity building activities should focus on needs expressed by the actors whose skills and knowledge the networks are aiming to improve. They overwhelmingly pointed toward peerto-peer learning as an important aspect of these approaches and described learning as an important outcome in and of itself. An informant from MPAConnect sums it up in this way:

\begin{abstract}
"One of the most important impacts we can have is just to help facilitate that learning between managers...many of these managers are isolated most of the time and don't have the opportunity to learn from the successes and failures of others. And so the whole point of MPAConnect is helping those managers learn from the expertise and experience of other marine protected area managers who are facing the same challenges and have many of the same goals and objectives that they do. It's created a sustained community among the 33 MPA sites that we now have in the network."
\end{abstract}

Some networks will provide broad or targeted responses, by way of learning exchanges or training activities, to tackle ongoing and emergent environmental issues. Experts, advisors, and knowledgeable peers are brought in, models for success are provided, and participants are equipped with tools or knowledge to execute changes or improvements in management (Bustamante et al., 2018; Davis et al., 2018). For example, in 2018 MPAConnect organized a training activity on how to handle a new coral tissue loss disease that MPA managers in Mexico had identified as a growing problem for them. Attendees came away better equipped to identify the disease and work with their local governments to navigate legal processes, comply with applicable regulations, and treat affected corals. A different informant from MPAConnect highlights the value of these types of meetings where managers learn from one another and from others:

"The outputs from the meeting directly targeted the needs expressed by the managers - they asked for a template monitoring and response plan that they could easily adapt and tailor to their own sites and countries, which we've since produced and is in use...There were excellent efficiencies that came from a subset of MPA managers working with me on developing these outputs, which we then shared with the rest of the network to save them from re-inventing the wheel."

While many of the marine-related learning networks in our study do not appear to explicitly target individual empowerment, informants from networks such as SMART Seas, MIHARI, and TBTI still mentioned empowerment as an important, additional outcome. Pietri et al. (2015) and Christie et al. (2016) found that capacity building can result in empowerment in the context of CTI-CFF and their regional exchanges. Our informants from CTI-CFF supported these conclusions. For example, they related how CTI-CFF launched the Women Leaders Forum in 2014, which specifically aims to empower women to engage in decisionmaking processes related to coastal and marine conservation programs. The forum has helped over 300 women develop as leaders in coral reef conservation and sustainable fisheries fields in the Coral Triangle region. Although few studies have set out to establish the extent of the relationship between capacity building and empowerment in other marine-related learning networks, these networks do expose people to opportunities in conservation and management fields by providing them with a variety of arenas and platforms to share their perspectives, learn new skills, and develop into better educators and leaders (Jupiter et al., 2014; Cleveland et al., 2015). Informants also described how these networks can reduce resource, accessibility, and equity barriers by connecting members with varied backgrounds and across stratified social and professional hierarchies. For example, the PTLC climate network brought teachers together with fishermen, scientific experts, and other members of society to exchange knowledge and information about climate change impacts and community health in Pohnpei. An informant describes a first grade teacher's perspective on the experience:

\footnotetext{
"She said, 'I'm communicating with scientists and they're actually listening to what I have to say about how I [teach] my first graders!' To her, that was...very valuable, it made her comfortable to where she felt like they're also learning from [her]...she had something valuable to contribute to people coming together."
}

While some marine-related learning networks directly aim to empower participants or facilitate professional development, informants from nearly all networks in our study discussed these outcomes as potential indirect results of their activities and training workshops. Overall, the strength of the connection between capacity building and empowerment varies widely across the marine-related learning networks included in this study.

\section{Essential Attributes of Effective Marine-Related Learning Networks}

In order to achieve the outputs and outcomes identified in Table 2, a variety of conditions and approaches emerged as key enabling factors for the networks included in our study. Here, we highlight four of the most important attributes of effective marine-related learning networks that emerged from our study: they (1) define their universe in the development stage; (2) build trust and commit to longevity; (3) facilitate equitable participation and knowledge sharing; and (4) establish responsible and sustained coordination and leadership.

\section{Defining the Purpose of the Network}

The genesis phase of a marine-related network is a critical moment that can encourage a network's success and longevity or, alternatively, severely undermine its functionality. In the early stages, it is necessary to identify the scope of the network, without which it may not be able to survive and grow (Biermann et al., 2019). This process was described by an informant from Big Ocean, "first things first, take an inventory of what's whatdefine your universe." This same idea was reiterated by numerous informants as they reflected on the iterative challenge they faced when determining the scope of their networks. This process consists of network leaders clearly defining: (1) why the network is needed, (2) what the goals of the network are, (3) the actors the network intends to target or the participants the network will engage with, (4) the process by which the network will work toward its goals, and (5) how the outcomes will meet the intended goals. Although the ever-evolving process of "defining 
your universe" is difficult, it is necessary for the development, formation, and survival of a network.

In particular, determining network goals is critical given the recent research indicating that environmental governance is undergoing a major change from the dominance of rulebased approaches to goal-based approaches (Kanie et al., 2019). Marine-related learning networks are particularly suitable for goal-based approaches given their potential for collaborative processes involving a broad range of stakeholders that change over time through meetings and continuous discussions (Kanie et al., 2019). Determining the goals of a network is a twofold process that involves considering both the needs of participants in the network as well as the communities they work with and the skills, expertise, and knowledge that the network can provide. An informant from the PTLC climate network described the importance of leveraging expertise during this process:

\begin{abstract}
"We take a very place-based approach to figuring out what the people in that place see as what they're lacking, and if there's any way that we could help by bringing in our expertise. What do they need to know and can we actually help them solve that problem?"
\end{abstract}

This process is particularly important in situations of limited resources and time. An informant from MPAConnect emphasized this point: "taking this capacity needs approach has been really valuable in helping to allocate scarce resources, and also in helping to justify where and why you're targeting resources." This requires efficient communication with and between members to make sure the network is representing them, and to determine the priorities and goals of the network. Otherwise, the network risks producing redundant or unnecessary information that could limit participation or the sustainability of the network. When thinking about redundancy, it is also important to consider the overlap with other external or partnered networks, institutions, or organizations. An informant from the Future Earth Ocean KAN noted that, "the large part of the success of these learning networks or knowledge-action networks is filling a gap and not duplicating something that's already existing."

Informants also advised starting small and working incrementally to allow the network to manage growth and expectations. Dealing with network growth can be challenging, particularly in the absence of financial support, clearly defined goals, or the ability to leverage collective action. Informants often talked about how many additional activities they would do if they had both the administrative capacity and funding, but also mentioned that it is wise to limit, or "define your universe" to what is feasible given available resources. This approach is key in part because learning networks should be long-term investments (though some networks start out with an ending date), and their value is derived from developing lasting relationships and fostering trust, which facilitates meaningful exchange and learning (Chandler and Kennedy, 2015; Christie et al., 2016). In some cases when network funding is tied to the efforts of external NGOs or agencies, this outside influence can impose priorities that are at odds with the needs of the network and the communities they work with (Scarf and Hutchinson, 2003).
Therefore, specific network needs should actively guide the genesis phase of networks.

The process of establishing these intentions and definitions is extremely important, but flexibility and adaptability are just as essential for ensuring that the network continues to respond to changing issues and the evolving needs of members. Because the challenges are always changing, an informant from TBTI explained that the skills needed to tackle such challenges may also change:

\footnotetext{
"You always need to be very flexible because every day is different. You never know what is going to happen. You have a week, weeks, months to plan and then it's a completely different thing so you have to be open to that. It's very dynamic - change is inevitable and it's continuous - so it's continuous to acquire new skills."
}

Numerous informants shared this view that flexibility is essential to a network's success and to ensuring the network has the best-suited structure for tackling issues related to the marine environment. Defining an overarching and cohesive purpose while also creating space for flexibility and adaptability allows the network to meet the needs of participants under changing conditions (Thompson et al., 2017). Flexibility, reflexivity, and learning are critical to the successful management and governance of marine resources and those who depend on them (Österblom and Folke, 2013).

\section{Trust and Relationship Building}

To effectively and efficiently leverage the resources and knowledge of the network's membership over the long term, networks must earn the trust and respect of their members, convincing them that they are not wasting their time. As an informant from PIMPAC said, "I think one of the foundational elements for a learning network is to have trust." Numerous informants echoed this same sentiment and noted the interconnectedness of trust and flexibility in their approach as the needs of network members changed over time. In order to build that trust, networks must be reliable and responsive in order to demonstrate that engaging is worthwhile. An informant from Big Ocean shared, "You have to create the conditions where people have trust and are willing to be vulnerable and bring the real issues to the table." We found that effective networks foster trust through two main avenues: engaging with their participants in person and making long-term commitments to the communities they work with.

\section{Engaging in Person}

Across the board, informants lauded in-person activities as a critical relational component of network communication (Cohen et al., 2012; Pietri et al., 2015). Communicating online is helpful for sustaining engagement and sharing information, but face-to-face interactions among network members makes communication more effective overall by creating connections and building relationships, which foster trust (Iwamoto et al., 2019). When trusting relationships are established, more meaningful learning and dialogue are enabled in the network (Chandler and Kennedy, 2015). 
"I think that there's a lot lost when local people don't interact directly and don't converse directly with scientists. And I think that in having learning networks, you're building trust... the benefit of a learning network is becoming a face, and not just like another one-page memo about the impacts of something coming at you."

- Informant, PTLC climate network

By establishing such relationships, participant perceptions change, allowing them to view one another as resources and expanding their available sources of knowledge and expertise (Keast et al., 2004). The density of such trust in a learning network is related to the modes of communication and coordination utilized, with in-person activities and their associated high levels of informal interaction leading to the most trust (Provan and Kenis, 2008). By bringing people together in person, networks create space for the development of friendships, and interaction outside of events at meals and during free time. In this way, the process of in-person communication and building trust within the network is an outcome in and of itself that is critical to network structure (Philbin and Linnell, 2013).

Regular gatherings and meetings are often cited as important components of achieving this collective outcome. As another informant from MedPAN puts it, "we really make sure that people can really meet regularly, every year, so that you start to build a family. This is really key for MedPAN." These meetings allow for informal interactions between network members to take place. These interactions may be just as important as formal meetings or sessions for motivating members to push through challenges at work and sustain the momentum for networks to achieve their conservation and management goals. Informants also acknowledged that facilitation of in-person encounters was especially important for engaging diverse participants who otherwise might feel out-of-place at a table with scientists and academics. A longtime informant from Big Ocean links the development of personal relationships to network success:

"An important thing is making them [network meetings and activities] fun and then also trying to not just make this all about work, but finding ways... where people get to know each other on a personal level because that is really what's going to carry these networks long term."

Personal connection constitutes an essential element of strengthening ties within and between networks (Alexander et al., 2017). Our informants affirmed the value of interpersonal relationships for their learning networks and emphasized that using virtual, online engagement platforms works effectively only after establishing a connection in person. As explained by an informant from CTI-CFF,

\footnotetext{
"You've got to talk to people in person and have meetings...just having a network through the internet is not going to work in the long run. You can use it for day-to-day things, but not for building the real relationships that are important."
}

The social components of in-person activities engage and retain people within a network. For this reason, multiple informants shared that online platforms cannot replace inperson meetings-they can augment and increase the number of activities and information exchanged, but they cannot entirely substitute for them.

\section{Committing to the Long-Term}

Our findings also indicate that a marine-related learning network's longevity is integral for building trust. Many informants emphasized their network's prolonged and consistent presence in the region as a key component of establishing credibility, maintaining member involvement, and achieving successes. Aswani et al. (2017) support this finding and identify the provision of practitioners with time and tools to inform and improve local resource management programs as a critical component of management capacity building. Unlike many environmental projects and initiatives that occur on short time scales with clear start and end dates, the vast majority of marine-related learning networks aim to operate over extended periods of time, and in many cases, indefinitely (Chandler and Kennedy, 2015; Gardner et al., 2018). The long-term nature and face-to-face components of networks build strong relationships and lasting connections between network members. As a result, these learning networks act as sources of motivation and support for members that often work in isolated or difficult-to-reach areas or in management settings with few peers or co-workers present (Cummings and van Zee, 2005; Food Agriculture Organization of the United Nations [FAO], 2017). Terms like "trust," "family," and "community" were often used by informants to describe the relationships that develop and the strong sense of community that arises due to network activities:

"[Big Ocean] feels kind of like a family. The people who come to new [network meetings], that's one of the first things they remark on is, 'wow, it feels like you guys have known each other forever and thanks for letting me in on the family.' "-Informant, Big Ocean

Twenty-three key informants (over $50 \%$ of our sample) used the terms "trust," "family," or described "strengthening community" or "cultivating relationships" when discussing the definition of their network, lessons learned, outcomes, and participant engagement. These informants represented 11 of the 16 networks included in this study.

Longevity allows networks to develop trust with members and communities, nurturing long-term relationships that pay dividends in the form of improvements in marine management, ocean and coastal governance, or-in some cases-empowerment. In addition, this builds resilience within networks to adapt and continue generating positive outcomes despite changes in leadership within the network, staff turnover in government agencies or management offices, or other external political and environmental influences. Overall, a network's ability to react and succeed in the short-term is predicated on trust established in the long-term.

\section{Facilitating Equitable Participation and Knowledge Sharing}

The core of any network begins with human connection. Successful participation is essential to bring about knowledge and opportunities for learning; without it the network would not exist. For many of the marine-related learning networks in 
our study, this is done through dynamic participation over long periods of time, in contrast to static traditional ocean governance structures, which often fail to adapt or consider the changing needs of local communities (Lemos and Agrawal, 2006; Young et al., 2007; Cárcamo et al., 2014; Tschirhart et al., 2016). As an advisor from a global network noted, "You cannot impose something from outside. You have to work with people, and it takes a lot of time...the key element is working with people." This focus on inclusive participation is a core feature of many marine-related learning networks, and consists of three primary components: engagement, subverting knowledge hierarchies, and building partnerships.

\section{Engagement}

The ability to consistently attract, engage, and retain participants in learning networks is challenging, but when cultivated effectively is a key ingredient for success. This challenge is particularly salient for those networks that work to amplify the voices of those who are underrepresented or have not been included in ocean governance decision making. In many cases, networks draw participants from a wide range of geographies, backgrounds, and cultures who may not otherwise interact. In order to ensure that these new interactions are productive, networks must provide opportunities for participants to build social capital through engaging with one another, realizing their shared values, and cultivating a sense of belonging to the network community (Cummings and van Zee, 2005; Fazey et al., 2007; Philbin and Linnell, 2013; Friedlander, 2018).

Informants frequently mentioned that creating this strong sense of community can encourage and facilitate wider participation in the network. In addition, cultivating a network environment where participants feel valued and supported encourages more honest and meaningful engagement, enabling the expression of diverse opinions and needs. McMillan and Chavis (1986) define a sense of community as, "a feeling that members have a belonging, a feeling that members matter to one another, and to the group and a shared faith that member's needs will be met through their commitment together" (p. 9). Such a shared commitment within a network is key to make sure participants are supported. This sense of community is developed by creating space to contribute and promoting the formation of personal connections and friendships:

"... people like that sense of community, they like to know that if they move forward, they're not alone. They're part of the community. If they trip up or if they struggle on something, there's a community they can reach back out to."

- Informant, PIMPAC

As participants develop these relationships and become comfortable with being vulnerable, the network is better able to support them and address their challenges. This is especially important because in many cases participants need a space in which to find new sources of inspiration and share their successes, challenges, and failures.

Learning networks also attract and retain participants by offering opportunities to develop professional skills such as public speaking, technical and organizational training, and other leadership abilities. In learning networks, this expertise often comes from the participants within the network who are personally engaged with the issues on the ground, as opposed to more distant network staff. As more participants with varied skills and knowledge become involved, the expertise within the network grows and its overall value for each participant increases. While professional development opportunities are often what attracts participants to engage with a network, our informants related that a participant's sustained involvement is often tied to the development of personal relationships and the overall growth of a strong network community.

The challenges facing collaboration in networks also emerge from the eclectic nature of network participant backgrounds and roles. The networks we interviewed included members ranging from park employees to small scale fishers; concerned locals to international NGOs; and volunteer activists to professional scientists. Networks' commitment to developing a sense of community between diverse participants offers opportunities for negotiation of differences even through difficult conversations around conflicts over authority, strategy, and knowledge.

\section{Respecting Knowledge and Subverting Hierarchies}

Informants referred to a range of systems and sources of knowledge exchanged within networks, which generally relate to the shared goal of capacity development to support decision making, inform policy, and make research more applicable to management. Our informants identified that the knowledge shared in their networks included technical information (including western science), personal experience-based knowledge and practical skills, and traditional ecological knowledge.

Informants discussed the importance of integrating traditional or local ecological knowledge into network activities, as well as knowledge across different disciplines, geographies, and age groups. Learning networks with more community-focused goals and priorities discussed knowledge in terms of participatory value and highlighted the situated needs of the population the network serves. Some informants suggested that using existing institutions and structures makes it easier and more effective to include community members in network decisionmaking and other processes. However, this approach carries the risk that institutions' existing norms and cultures may not encourage horizontal knowledge exchanges integral to learning networks. Diversifying the voices included in the network introduces different ways of knowing that may not have been previously represented or acknowledged. The inclusion of diverse perspectives creates more opportunities for participants to reflect and learn (Fletcher et al., 2009). As one informant from Big Ocean puts it:

\footnotetext{
"...none of us have all the answers. And we need an input from everyone-from local people, stakeholders, industry people, rights holders, indigenous groups. A lot of these areas really depend on that sort of input. And you can't teach that, it almost has to come from within."
}

Having local contacts within key institutions is essential to make sure the network operates respectfully and can 
deliver relevant outcomes to those with whom the network engages.

It is also important to strike a balance between the transfer of knowledge and the production of knowledge through novel processes. Several informants explained that their networks avoid the issue of "reinventing the wheel" by connecting participants with existing resources in order to address issues or overcome technical obstacles that others have previously faced. As network participants and members often seek western science and technical expertise, this presents marine-related learning networks with an additional challenge. They must take care to convey academic and scientific knowledge in a way that is tailored to fit local needs and does not invalidate cultural norms or local practices. Speaking on this topic, another informant from Big Ocean said:

\footnotetext{
"We don't tell countries what to do. How could we? What do we know about their country? Nothing. But what we can do is share stories from the countries where these [technical or management interventions] have gone in, and share lessons learned."
}

Because knowledge is based on interpretation, it can become personal, preferred, and biased depending on the interpreter (Cvitanovic et al., 2015). Informants advised frequent communication and collaboration with the targeted network members and participants in order to ground-truth the approach before application (e.g., programs, activities). Similarly, informants suggested that cultivating meaningful participation in a network is more effective when those invited to participate feel that they are respected and welcomed, regardless of their background. Learning networks can facilitate safe spaces where individuals from all levels of education and experience can come together to collaborate and learn from each other. An informant from a network in Micronesia shared their insight on the importance of creating a space that equally values everyone's contributions:

\footnotetext{
"In Micronesia...people are still sensitive about the educated and the non-educated-[there was an] old man from the village.he said he only made it to like second, third grade because he didn't like sitting in a classroom for hours and hours and listening to one person talk. He learned better by doing...these learning networks are bringing people [together] from every aspect of [the community] and all levels of education."
}

In this type of space, the reduced dependency on knowledge hierarchy facilitates more diverse participation, which enriches the experience of everyone involved. In this way, learning networks avoid the problematic narrative of "educating" the uneducated-also known as "knowledge banking"and instead acknowledge the value of varied perspectives and experiences that facilitate learning for everyone at the table (Freire, 1970). Transmission of knowledge between peers, or "horizontal learning exchange," becomes even more important for collaborations within the Global South by offering the opportunity for community-centered alternatives to hierarchical institutional communication flows (Bradlow, 2015). Although our informants emphasized the value of in-person communication, horizontal exchange also benefits from the use of online platforms which provide essential facilitation space outside of traditional power structures (Castellis, 2007). Therefore, both technological and relational pathways must be included in democratizing knowledge exchange.

There is no standardized ideal design for the iterative process that marine-related learning networks undertake to bridge and fill knowledge gaps. Each network will approach knowledge exchange or creation differently depending on context, available resources, and objectives. Despite these differences, these networks emphasize reflexivity, collaboration, and relationship building. These practices align with the four principles of co-production: their processes are context-based, pluralistic, goal-oriented, and interactive (Norström et al., 2020). Our informants collectively indicated that through co-production, learning networks can remove disciplinary boundaries between scientists, policymakers, practitioners, and decision-makers. This approach promotes mutual learning, generates social capital, and enables governance transformation (Cash et al., 2003; Norström et al., 2020).

The capacity of networks to create space for co-production leverages participation to subvert the hierarchies often present in ocean management. An informant from SMART Seas shared how the network helped level the playing field within the context of an environmental conservation and management agency in East Africa:

“...SMART Seas had broken this hierarchy, because among this group from different levels we had the boat driver who became the coral specialist and this other guy who became the sea grass specialist. The senior warden was asking them for information. They became his experts. It felt to me that it brought everyone to the same level, where everyone was being respected for their knowledge, and that was great."

As many of these networks are providing knowledge in a space that has been dependent on top-down and expert-led approaches, achieving equal footing and building trust requires transparency (Christie et al., 2017). An informant from the Future Earth Ocean KAN noted the importance of transparency as a tool to break hierarchical structures, "[Networks] can provide that critical knowledge in an open and transparent fashion, which helps even the power." Rather than arriving in a geography or community with a predetermined set of goals, methods, and desired outcomes, networks offer an opportunity to engage in truly dialogical learning and problem-solving with affected stakeholders (Freire, 1970). This transparency is critical to ensuring goal clarity and promoting the usefulness of diverse knowledge.

\section{Partnerships}

Our analysis indicates that increasing the representation of the localities where a network conducts work leads to innovative methods of creating knowledge and helps improve how that knowledge is communicated and shared. Pursuant to the goals and target audience of the network, informants related that a network should purposely package, translate, and present knowledge and information so it is accessible and actionable for those who will use it. Connecting with people and organizations 
on the ground to help deploy vital knowledge and institute conservation interventions is essential, and without the right connections, networks may be limited in their ability to address environmental challenges. Many informants emphasized the essential role of partnerships and collaborations, with other local networks and organizations in particular, in order to better integrate activities into local context and build trust with relevant actors. An informant from RRN explains:

\footnotetext{
"In order to be grounded and relevant, we worked with a local network, or when there weren't local networks in existence, we at least had local key people that knew who was on the ground doing what. If there's a local network, it's critical, because they're going to have a better understanding of everything than you would as a global network."
}

By partnering and working with more localized networks, institutions, and individuals, marine-related learning networks are able to increase their reach by providing them with important social capital and helping them ensure that their initiatives are most appropriate for their intended audiences (Rosen and Olsson, 2013; Christie et al., 2017).

\section{Sustained Coordination and Leadership}

A learning network's leadership, including their specific responsibilities in running them, emerged from our analysis as a key element of operational effectiveness. The administrative burden of managing networks is immense and requires significant dedicated staff time. A large majority of informants identified funding as a main challenge for their network, and any available funds are often dedicated for activities and projects as opposed to maintaining the network's administrative capacity. Nevertheless, informants specified that establishing and financially supporting a coordinator position was vital for their network's success, as illustrated by an informant from CTI-CFF: "We always come back to the principles of a learning network. You need a clear purpose and a dedicated coordinator, some key resources to take it off. Otherwise it's not going to really happen."

The precise role of a coordinator may differ between learning networks, but the position is generally one of planning, organizing, communicating, fundraising, and managing critical operational tasks in order to keep the network working toward its goals. Coordinators were often likened to the "motor," "driver," or "champion" that keep the network relevant, engaged, and positioned as an effective conduit of knowledge exchange. Because of their varied responsibilities, network coordinators have to step into various roles and use diverse skills, such as the ability to mediate across sectors and in situations where people are outside of their comfort zones. This position is sometimes called a "broker" (Bessant and Tsekouras, 2001) or a "weaver" (Philbin and Linnell, 2013) and is described as someone who is able to both arrange and manage the various mechanisms of the network while also facilitating and motivating learning, connection, and exchange (Keast et al., 2004). One informant said, "if you don't have good coordination, don't even start a network, because it's useless. If it's not somebody's day-to-day job thinking about how this thing is running and making things move, it's just not going to happen."
The suite of skills and leadership qualities required to ensure efficacy in something as dynamic and complex as a marinerelated learning network are heavily based in communication skills, awareness, inclusivity, and the capacity to manage and forge relationships with and between actors (Heifetz, 1994; Jacobs et al., 2005; Feldman and Ingram, 2009; Manolis et al., 2009). Our findings indicate that an effective coordinator is someone who is able to stay in close, meaningful contact with the people and communities with whom the network engages. This includes being responsive to questions, staying attuned to challenges and on-the-ground realities, and translating evolving needs into action by the network. Informants also emphasized the value of diversity in network leadership, particularly with regard to career stages and the engagement of early career professionals, who can bring valuable energy and fresh ideas to the network.

Providing organized trainings, workshops, and mentorships to capacitate individuals to be more effective network members and leaders is critical (Manolis et al., 2009). The growth and development of new leaders can actually be used as a metric for measuring a network's success in a particular region.

\footnotetext{
"We've seen a lot of the people that we've worked with-we kind of call them 'gen-one PIMPAC-ers'-now they're in leadership positions... and if you talk to them they'll say things like, 'I had no clue about anything when I started back in this organization, but it was through all the training and support I got with PIMPAC that I really understood how to go about management work with communities. "'-Informant, PIMPAC
}

The retention of coordinators and other leaders within the network is also key. Because coordinators are responsible for preserving existing relationships and encouraging new ones, they need to be able to understand the context and actors involved and act effectively within that complex landscape. As coordinators will inevitably change over the course of a network's lifetime, informants noted that networks should develop clear governance systems or procedures that support smooth transitions between these key leaders. This provides new leaders with a better chance to succeed, can help reduce leadership burn-out, and assists in sustaining trust in the network.

The ability to convince others of the value of a network, a process made easier by trustworthy leaders, is important because efforts to improve large-scale resource management are abundant and wide-ranging in both scale and scope (Bidwell et al., 2013). With so many actors attempting to provide solutions or gain influence with a region or community, emerging network leaders often find themselves entering into crowded decision-making arenas, where gaining respect, trust, influence, and sharing new ideas is a challenge. Without the ability to gain the trust of local leaders and the communities with whom networks engage, attempts at sharing knowledge or facilitating better management practices can be met with indifference or dismissiveness (Hahn et al., 2006; Cohen et al., 2012).

There is no one-size-fits-all approach for managing networks, but investing in administrative capacity, as opposed to projectspecific investments, is vital to navigating the dynamic process of figuring out how to best set up management. In the 
absence of a coordinator, a decentralized learning network can mainly expect to diffuse knowledge, rather than provide meaningful connections and active information exchange. Regardless of the title, this leadership role-which often goes far beyond administration-is crucial to achieving successful outcomes.

\section{CONCLUSION}

The results presented in this study demonstrate that learning networks fulfill a crucial need in ocean governance contexts by building capacity and connecting practitioners, managers, and resource users, thereby shifting management and policy paradigms toward more inclusive, equitable, and collaborative approaches. The marine-related learning networks included in this study aim to support healthy marine environments and to improve the lives of those who depend on ocean resources. While measuring tangible progress toward this goal is often difficult, our results show that the outcomes that networks are generating through knowledge creation, knowledge transmission, and capacity-building are improving the governance of relevant socio-ecological systems.

We must note that marine-related learning networks face myriad challenges and are not always able to achieve their goals. In cases where our informants were unable to point toward multiple clear-cut examples or instances of success, networks typically exhibited one or both of two conditions: (1) they were established relatively recently, and/or (2) they are struggling to "define their universe." Beyond the fact that newly established networks have had less time to generate outcomes, they also lacked sufficient time to establish strong relationships and connections with their membership. The trust developed within networks over time is an extremely important factor in galvanizing engagement and achieving successes. Our results indicate that networks with more generalized missions or broader scopes of work tend to encounter more challenges within this process. These networks experience difficulties linking their activities to substantive outcomes when they lack well-defined goals and priorities or have been unable to establish rational metrics of success or a practical theory of change. Both of these conditions are exacerbated in situations where scarce financial resources further limit the capacity of the network to achieve its desired impacts.

Nevertheless, these obstacles are not insurmountable. Our findings suggest that learning networks are needed to fill gaps in ocean and coastal governance and to build capacity of those working in marine fields by connecting individuals and communities who otherwise may not interact, or to empower marginalized constituencies. In many cases, the need for a network arises from pressing issues that demand urgent action yet lack solutions in existing governance structures. When networks are efficiently and effectively run, they serve as conduits for the translation, aggregation, validation, and dissemination of knowledge and information that inspires action and supports more inclusive, sustainable, and adaptive ocean governance systems. While marine-related networks are not a panacea for ocean and coastal issues, they allow for the inclusivity of societal actors that have previously been left out of environmental governance management regimes.

Despite this value, certain mechanisms still exist outside of network control that can inhibit whether or not the outputs that result from network activities have the intended impacts. For example, after transferring useful, usable knowledge into the hands of decision makers, those decision makers may refuse to acknowledge or utilize that information. This is one critical obstacle to effective knowledge dissemination (Knott and Wildavsky, 1980). For networks that work toward producing knowledge to encourage improved policy implementation, this barrier poses a significant challenge. The second and third obstacles are a lack of access to existing knowledge, as well as distrust or insufficient dialogue between those with knowledge and those who need it. Our findings indicate that in marinerelated contexts, network systems can help circumvent the latter two obstacles by bringing people together in inclusive environments to share knowledge with one another and develop trust, effectively building their capacity to inform policy and improve management.

This study presents a wide-reaching first look at the general role of marine-related learning networks in ocean governance across many contexts. Future research on this topic could expand upon any of the major thematic sections of this paper. Additional studies could also focus on any of these themes or other lessons learned for specific subsets of marine-related learning networks, such as MPA networks, knowledge-sharing networks, or research networks. Examinations of marine-related learning networks that incorporate the perspectives of participants and non-staff members, rather than administrators and leaders, would provide a more comprehensive understanding of how networks operate and influence participants. Similarly, interviews with donors would contribute data on funder preferences for network programs and to what extent learning networks would fall within their priorities and norms.

As a result of the COVID-19 pandemic, global society dramatically increased its use of online video platforms to host virtual meetings, conferences, webinars, and workshops. The convenience and cost-cutting advantages of these platforms could impact their use and application within marine-related learning networks in the future, even if international travel and in-person interactions return to pre-pandemic levels. However, we expect in-person meetings and exchanges to continue to play fundamental roles within most networks, given the importance that informants placed on face-toface communication and informal interactions for building trust and establishing supportive network communities. Future research could explore network participants' attitudes toward changes implemented as online communication platforms rise in popularity.

While knowledge and uncertainty for decision makers present major challenges for ocean governance, creating adaptation networks, improving community participation, co-producing and integrating knowledge, and improving coordination and communication will be integral components of effective solutions (Funtowicz and Ravetz, 1993; Bindoff et al., 2019). Our research 
demonstrates that marine-related learning networks have the potential to address challenges created and exacerbated by climate change and other complex problems involving ocean and coastal systems. Such seemingly intractable problems require knowledge creation and knowledge-to-action systems to complement the traditional scientific-led policy making. However, since networks are not immune to external influences, including the agendas of funding entities, political turbulence, and ideological shifts (Gerhardinger et al., 2018), simply creating more learning networks to operate and engage in marine contexts is not the solution. Learning networks are most effective when they are developed in response to identified needs of marine managers, resource users, governments, resource users, activists or other communities. When there is a clear lack of information or insufficient capacity to address a shared challenge, marine-related learning networks leverage the trust and partnerships they build to collectively address complex ocean and coastal challenges.

\section{DATA AVAILABILITY STATEMENT}

The raw data supporting the conclusions of this article will be made available by the authors, without undue reservation, to any qualified researcher.

\section{REFERENCES}

Ackoff, R. L. (1974). Redesigning the Future: A Systems Approach to Societal Problems. New York, NY: Wiley.

Adler, E., and Haas, P. (1992). Conclusion: epistemic communities, world order, and the creation of a reflective research program. Intern. Organ. 46, 367-390. doi: 10.1017/S0020818300001533

Alexander, S. M., Armitage, D., Carrington, P. J., and Bodin, Ö. (2017). Examining horizontal and vertical social ties to achieve social-ecological fit in an emerging marine reserve network. Aquat. Conserv. Mar. Freshwater Ecosyst. 27, 12091223. doi: 10.1002 aqc. 2775

Apostel, L. (1972). Interdisciplinarity; Problems of Teaching and Research in Universities. Paris: Organisation for Economic Cooperation and Development.

Armitage, D., De Loë, R., and Plummer, R. (2012). Environmental governance and its implications for conservation practice. Conserv. Lett. 5, 245-255. doi: 10.1111/j.1755-263X.2012.00238.x

Aswani, S., Albert, S., and Love, M. (2017). One size does not fit all: critical insights for effective community-based resource management in Melanesia. Mar. Policy 81, 381-391. doi: 10.1016/j.marpol.2017.03.041

Berkes, F. (2008). Sacred Ecology, 2nd Edn, New York, NY: Routledge. doi: 10.4324/ 9780203928950

Berkes, F. (2009). Evolution of co-management: role of knowledge generation, bridging organizationsand social learning. J. Environ. Manag. 90, 1692-1702. doi: 10.1016/j.jenvman.2008.12.001

Bessant, J., and Tsekouras, G. (2001). Developing learning networks. AI Soc. 15, 82-98. doi: 10.1007/BF01205739

Bidwell, D., Dietz, T., and Scavia, D. (2013). Fostering knowledge networks for climate adaptation. Nat. Clim. Chang. 3, 610-611. doi: 10.1038/nclimate 1931

Biermann, F., Betsill, M. M., Burch, S., Dryzek, J., Gordon, C., Gupta, A., et al. (2019). The earth system governance project as a network organization: a critical assessment after ten years. Curr. Opin. Environ. Sustain. 39, 17-23. doi: 10.1016/j.cosust.2019.04.004

Bindoff, N. L., Cheung, W. W. L., Kairo, J. G., Arístegui, J., Guinder, V. A., Hallberg, R., et al. (2019). "Chapter 5: Changing ocean, marine ecosystems, and dependent communities," in IPCC Special Report on the Ocean and Cryosphere

\section{AUTHOR CONTRIBUTIONS}

$\mathrm{KD}, \mathrm{MS}, \mathrm{HB}, \mathrm{BK}$, and $\mathrm{DB}$ conducted the research, performed the analysis, and wrote the manuscript. LG and PC provided supervision, guidance, and review. All authors conceptualized the project, designed the methodology, informed the analytic process, and contributed to the editorial process.

\section{ACKNOWLEDGMENTS}

This paper is the result of a collaboration with members of PainelMar, to whom we express sincere thanks, specifically: Leandra Gonçalves, Adayse Bossolani, Sérgio Mattos, and Marinez Scherer. Additionally, the faculty and staff at the University of Washington's School of Marine and Environmental Affairs were instrumental in getting this project off the ground. We are also grateful to the Dr. Clyde Snow Fund for Latin American and Caribbean Studies for supporting the presentation of our initial findings at the 2020 Brazilian Oceanic Horizon Conference. We are indebted to each and every one of our informants, who graciously took the time to speak with us in depth about their networks. We also would like to acknowledge the guidance and contributions of Petra McGowan and Emma Doyle.

in a Changing Climate, eds H.-O. Pörtner, D. C. Roberts, V. Masson-Delmotte, P. Zhai, M. Tignor, E. Poloczanska, et al. (Geneva: IPCC).

Borgatti, S. P., and Halgin, D. S. (2011). On network theory. Organ. Sci. 22, 1168-1181. doi: $10.1287 /$ orsc. 1100.0641

Bradlow, B. H. (2015). City learning from below: urban poor federations and knowledge generation through transnational, horizontal exchange. Intern. Dev. Plan. Rev. 37, 129-142. doi: 10.3828/idpr.2015.12

Bustamante, G., Vanzella, A., Glazer, R., and Collado-Vides, L. (2018). The evolution of the Caribbean marine protected area management network and forum (CaMPAM): 20 years of the regional multidimensional program for strengthening MPA practitioners. Gulf Caribbean Res. 29, GCFI1-GCFI9. doi: $10.18785 /$ gcr.2901.01

Cárcamo, P. F., Garay-Flühmann, R., and Gaymer, C. F. (2014). Collaboration and knowledge networks in coastal resources management: how critical stakeholders interact for multiple-use marine protected area implementation. Ocean Coast. Manag. 91, 5-16. doi: 10.1016/j.ocecoaman.2014. 01.007

Cash, D. W., Clark, W. C., Alcock, F., Dickson, N. M., Eckley, N., Guston, D. H., et al. (2003). Knowledge systems for sustainable development. Proc. Natl. Acad. Sci. U.S.A. 100, 8086-8091. doi: 10.1073/pnas.1231332100

Castellis, M. (2007). Communication, power and counter-power in the network society. Intern. J. Commun. 1:29.

Chandler, J., and Kennedy, K. S. (2015). A Network Approach to Capacity Building. Washington, DC: National Council of Nonprofits.

Christie, P., Bennett, N. J., Gray, N. J., Aulani Wilhelm, T., Lewis, N., Parks, J., et al. (2017). Why people matter in ocean governance: incorporating human dimensions into large-scale marine protected areas. Mar. Policy 84, 273-284. doi: 10.1016/j.marpol.2017.08.002

Christie, P., Pietri, D. M., Stevenson, T. C., Pollnac, R., Knight, M., and White, A. T. (2016). Improving human and environmental conditions through the Coral triangle initiative: progress and challenges. Curr. Opin. Environ. Sustain. 19, 169-181. doi: 10.1016/j.cosust.2016.03.002

Chuenpagdee, R., and Jentoft, S. (2013). Assessing governability - What's Next. MARE Public. Ser. 7, 335-349. doi: 10.1007/978-94-007-6107-0

Cicin-Sain, B., and Knecht, R. (1998). Integrated Coastal and Ocean Management: Concepts and Practices. Washington, DC: Island Press. 
Cisneros-Montemayor, A. M., Moreno-Báez, M., Voyer, M., Allison, E. H., Cheung, W. W. L., Hessing-Lewis, M., et al. (2019). Social equity and benefits as the nexus of a transformative Blue economy: a sectoral review of implications. Mar. Policy 109, 103702. doi: 10.1016/j.marpol.2019.103702

Clarke, M., and Stewart, J. (1997). Handling the Wicked Issues: A Challenge for Government. Birmingham: University of Birmingham, Institute of Local Government Studies.

Cleveland, J., Plastrik, P., Brandes, P., Sutherland, S., Ullman, M., and Anderson, R. (2015). Investing Strategically in Social-Impact Networks. Washington, DC: Island Press.

Cohen, P. J., Evans, L. S., and Mills, M. (2012). Social networks supporting governance of coastal ecosystems in Solomon Islands. Conserv. Lett. 5, 376-386. doi: 10.1111/j.1755-263X.2012.00255.x

Creech, H., and Willard, T. (2001). Strategic Intentions: Managing Knowledge Networks for Sustainable Development. Winnipeg, MB: International Institute for Sustainable Development.

Crowder, L. B., Osherenko, G., Young, O. R., Airamé, S., Norse, E. A., Baron, N., et al. (2006). American association for the advancement of science. Science 313, 617-618. doi: 10.1210/jcem-10-10-1361

Cummings, S., and van Zee, A. (2005). Communities of practice and networks: reviewing two perspectives on social learning. KM 4D, 8-22.

Cvitanovic, C., Hobday, A. J., van Kerkhoff, L., Wilson, S. K., Dobbs, K., and Marshall, N. A. (2015). Improving knowledge exchange among scientists and decision-makers to facilitate the adaptive governance of marine resources: a review of knowledge and research needs. Ocean Coast. Manag. 112, 25-35. doi: 10.1016/j.ocecoaman.2015.05.002

Davis, J., Stinson, S., and Wehner, N. (2018). As an MPA manager, it ̌s nice to know I'm not alone out there: Challenges, successes, and lessons from building effective MPA management networks (Part I - The global networks). Available online at: https://mpanews.openchannels.org/news/mpa-news/mpa-manager-its-niceknow-im-not-alone-out-there-challenges-successes-and-lessons (accessed February 10, 2020).

De Kraker, J., Cörvers, R., Valkering, P., Hermans, M., and Rikers, J. (2013). Learning for sustainable regional development: towards learning networks 2.0?. J. Clean. Product. 49, 114-122. doi: 10.1016/j.jclepro.2012.11.019

Fazey, I., Fazey, J. A., Fischer, J., Sherren, K., Warren, J., Noss, R. F., et al. (2007). Adaptive capacity and learning to learn as leverage for social-ecological resilience. Front. Ecol. Environ. 5, 375-380. doi: 10.1890/1540-929520075[375: ACALTL]2.0.CO;2

Feldman, D. L., and Ingram, H. M. (2009). Making science useful to decision makers: climate forecasts, water management, and knowledge networks. Weather Clim. Soc. 1, 9-21. doi: 10.1175/2009WCAS1007.1

Fletcher, S., Kawabe, M., Rewhorn, S., Knee, T. C., Emery, A., Wakita, K., et al. (2009). International learning pathways for coastal professionals: a japanuk example. Coast. Manag. 37, 154-169. doi: 10.1080/08920750902758499

Food Agriculture Organization of the United Nations [FAO] (2017). Report of the Fifth Global Fisheries Enforcement Training Workshop. Rome: FAO.

Freire, P. (1970). Pedagogy of the Oppressed. London: Bloomsbury Academic.

Friedlander, A. M. (2018). Marine conservation in Oceania: past, present, and future. Mar. Pollut. Bull. 135, 139-149. doi: 10.1016/j.marpolbul.2018.05.064

Fukuda-Parr, S., Lopes, C., and Malik, K. (eds) (2002). Capacity for Development: New Solutions to Old Problems. New York, NY: Earthscan.

Funtowicz, S. O., and Ravetz, J. R. (1993). Science for the post-normal age. Futures 25, 739-755. doi: 10.1016/0016-3287(93)90022-L

Gardner, C. J., Nicoll, M. E., Birkinshaw, C., Harris, A., Lewis, R. E., Rakotomalala, D., et al. (2018). The rapid expansion of Madagascar's protected area system. Biol. Conserv. 220, 29-36. doi: 10.1016/j.biocon.2018.02.011

Gerhardinger, L. C., Gorris, P., Gonçalves, L. R., Herbst, D. F., Vila-Nova, D. A., De Carvalho, F. G., et al. (2018). Healing Brazil's blue amazon: the role of knowledge networks in nurturing cross-scale transformations at the frontlines of ocean sustainability. Front. Mar. Sci. 4:395. doi: 10.3389/fmars.2017.00395

Gill, D. A., Mascia, M. B., Ahmadia, G. N., Glew, L., Lester, S. E., Barnes, M., et al. (2017). Capacity shortfalls hinder the performance of marine protected areas globally. Nature 543, 665-669. doi: 10.1038/nature21708

Glaser, B., and Strauss, A. (1967). The Discovery of Grounded Theory. London: AldineTransaction.

Hahn, T., Olsson, P., Folke, C., and Johansson, K. (2006). Trust-building, knowledge generation and organizational innovations: the role of a bridging organization for adaptive comanagement of a wetland landscape around Kristianstad, Sweden. Hum. Ecol. 34, 573-592. doi: 10.1007/s10745-006-9035-z Heifetz, R. A. (1994). Leadership without Easy Answers. Cambridge, MA: Belknap Press of Harvard University Press.

Iwamoto, M. M., Dorton, J., Newton, J., Yerta, M., Gibeaut, J., Shyka, T., et al. (2019). Meeting regional, coastal and ocean user needs with tailored data products: a stakeholder-driven process. Front. Mar. Sci. 6:290. doi: 10.3389/ fmars.2019.00290

Jacobs, K., Garfin, G., and Lenart, M. (2005). More than just talk: connecting science and decision making. Environment 47, 6-21. doi: 10.3200/envt.47.9. 6-21

Jupiter, S. D., Cohen, P. J., Weeks, R., Tawake, A., and Govan, H. (2014). Locallymanaged marine areas: multiple objectives and diverse strategies. Pac. Conserv. Biol. 20, 165-179. doi: 10.1071/PC140165

Kanie, N., Griggs, D., Young, O., Waddell, S., Shrivastava, P., Haas, P. M., et al. (2019). Governance for global sustainability is undergoing a major transformation from rule-based to goal-based. But with no compliance measures, success will require an unprecedented level of coherency of action founded on new and reformed institutions nationally and internationally. Sustain. Sci. 14, 1745-1749. doi: 10.1007/s11625-019-00729-1

Keast, R., Mandell, M. P., Brown, K., and Woolcock, G. (2004). Network structures: working differently and changing expectations. Public Admin. Rev. 64, 363-371. doi: $10.1111 / \mathrm{j} .1540-6210.2004 .00380 . \mathrm{x}$

Kelly, C., Ellis, G., and Flannery, W. (2018). Conceptualising change in marine governance: learning from transition management. Mar. Policy 95, 24-35. doi: 10.1016/j.marpol.2018.06.023

Klein, J. T. (2008). Evaluation of interdisciplinary and transdisciplinary research. a literature review. Am. J. Prevent. Med. 35, 116-123. doi: 10.1016/j.amepre.2008. 05.010

Knott, J., and Wildavsky, A. (1980). If dissemination is the solution, what is the problem? Knowl. Creat. Diffus. Utiliz. 1, 537-578. doi: 10.1177/ 107554708000100404

Lemos, M. C., and Agrawal, A. (2006). Environmental governance. Annu. Rev. Environ. Resour. 31, 297-325. doi: 10.1146/annurev.energy.31.042605.135621

Lincoln, Y. S., and Guba, E. G. (1985). Naturalistic Inquiry. Beverly Hills, CA: Sage Publications. doi: 10.1016/0147-1767(85)90062-8

Manolis, J. C., Chan, K. M., Finkelstein, M. E., Stephens, S., Nelson, C. R., Grant, J. B., et al. (2009). Society for conservation biology leadership: a new frontier in conservation science. Biology 23, 879-886. doi: 10.1111/j.1523-1739.2008. 01150.x

Matous, P., and Todo, Y. (2015). Exploring dynamic mechanisms of learning networks for resource conservation. Ecol. Soc. 20:236. doi: 10.5751/ES-07602200236

Maxwell, S. M., Hazen, E. L., Lewison, R. L., Dunn, D. C., Bailey, H., Bograd, S. J., et al. (2015). Dynamic ocean management: defining and conceptualizing realtime management of the ocean. Mar. Policy 58, 42-50. doi: 10.1016/j.marpol. 2015.03.014

McFarlane, C. (2009). Translocal assemblages: space, power and social movements. Geoforum 40, 561-567. doi: 10.1016/j.geoforum.2009.05.003

McMillan, D. W., and Chavis, D. M. (1986). Sense of community: a definition and theory. J. Commun. Psychol. 14, 6-23. doi: 10.1002/1520-6629(198601)14:1<6:: aid-jcop2290140103>3.0.co;2-i

MIHARI (2020). FAQs and Resources. Available online at: https://mihari-network. org/how/ (accessed March 10, 2020).

Mitchell, R. B. (2010). International Politics and the Environment. London: Sage Publications Ltd.

Norström, A. V., Cvitanovic, C., Löf, M. F., West, S., Wyborn, C., Balvanera, P., et al. (2020). Principles for knowledge co-production in sustainability research. Nat. Sustain. 3, 182-190. doi: 10.1038/s41893-0190448-2

Österblom, H., and Folke, C. (2013). Emergence of global adaptive governance for stewardship of regional marine resources. Ecol. Soc. 18:4. doi: 10.5751/ES05373-180204

Ostrom, E. (2007). A diagnostic approach for going beyond panaceas. Proc. Natl. Acad. Sci. U.S.A. 104, 15181-15187. doi: 10.1073/pnas.0702288104

Ostrom, E., Burger, J., Field, C. B., Norgaard, R. B., and Policansky, D. (1999). Revisiting the commons: local lessons, global challenges. Science 284, 278-282. doi: $10.1126 /$ science. 284.5412 .278 
Philbin, A., and Linnell, D. (2013). Funding Learning Networks for Community Impact. Third Sector New England. Available online at: https://tsne.org/ downloads/Funding-Networks-for-Community-Impact.pdf (accessed January $15,2020)$.

Pietri, D. M., Stevenson, T. C., and Christie, P. (2015). the coral triangle initiative and regional exchanges: strengthening capacity through a regional learning network. Glob. Environ. Chang. 33, 165-176. doi: 10.1016/j.gloenvcha.2015. 05.005

Poell, R. F., Chivers, G. E., Van der Krogt, F. J., and Wildemeersch, D. A. (2000). Learning-network theory. Manag. Learn. 31, 25-49. doi: 10.1177/ 1350507600311004

Pomeroy, R., and Douvere, F. (2008). The engagement of stakeholders in the marine spatial planning process. Mar. Policy 32, 816-822. doi: 10.1016/j.marpol. 2008.03.017

Provan, K. G., and Kenis, P. (2008). Modes of network governance: structure, management, and effectiveness. J. Public Admin. Res. Theory 18, 229-252. doi: 10.1093/jopart/mum015

Rittel, H. W. J., and Webber, M. M. (1973). Dilemmas in a general theory of planning. Policy Sci. 4, 155-169. doi: 10.1007/bf014 05730

Rosen, F., and Olsson, P. (2013). Institutional entrepreneurs, global networks, and the emergence of international institutions for ecosystem-based management: the coral triangle initiative. Mar. Policy 38, 195-204. doi: 10.1016/j.marpol.2012. 05.036

Rosenfield, P. L. (1992). The potential of transdisciplinary research for sustaining and extending linkages between the health and social sciences. Soc. Sci. Med. 35, 1343-1357. doi: 10.1016/0277-9536(92)90038-R

Scarf, C., and Hutchinson, K. (2003). "Knowledge networks for development: a participatory design approach," in Proceedings of the International Conference on the Convergence of Knowledge, Cultura, Language and Information Technologies, Alexandria.

Scarlett, L., and McKinney, M. (2016). Connecting people and places: the emerging role of network governance in large landscape conservation. Front. Ecol. Environ. 14, 116-125. doi: 10.1126/science.151.3712. 864-c

Shrivastava, P., Raivio, K., Kasuga, F., Tewksbury, J., Haines, A., and Daszak, P. (2016). Future earth health knowledge-action network. Public Health Rev. 37, 1-5. doi: 10.1186/s40985-016-0039-y

SocMon (2020). About SocMon. Available online at: https://www.socmon.org/ about.aspx (accessed March 2, 2020).

Strauss, A., and Corbin, J. M. (1990). Basics of Qualitative Research: Grounded Theory Procedures and Techniques. Newbury Park, CA: Sage Publications Inc.
The Heinz Center (2004). The John H. Heinz Center III for Science, Economics, and the Environment. Innovation by Design: Improving Learning Networks in Coastal Management, Environment. Washington, DC: The Heinz Center.

Thompson, K. R., Heyman, W. D., Peckham, S. H., and Jenkins, L. D. (2017). Key characteristics of successful fisheries learning exchanges. Mar. Policy 77, 205-213. doi: 10.1016/j.marpol.2016.03.019

Tobey, J., and Volk, R. (2002). Learning frontiers in the practice of integrated coastal management. Coast. Manag. 30, 285-298. doi: 10.1080/089207502 90022

Tschirhart, C., Mistry, J., Berardi, A., Bignante, E., Simpson, M., Haynes, L., et al. (2016). Learning from one another: evaluating the impact of horizontal knowledge exchange for environmental management and governance. Ecol. Soc. 21:41. doi: 10.5751/ES-08495-210241

Walton, A., White, A. T., Tighe, S., Aliño, P. M., Laroya, L., Dermawan, A., et al. (2014). Establishing a functional region-wide coral triangle marine protected area system. Coast. Manag. 42, 107-127. doi: 10.1080/08920753.2014. 877765

Weber, E. P., and Khademian, A. M. (2008). Wicked problems, knowledge challenges, and collaborative capacity builders in network settings. Public Admin. Rev. 68, 334-349. doi: 10.1109/EMR.2010.5559144

Wenger, E., McDermott, R. M., and Snyder, W. M. (2002). Cultivating Communities of Practice: A Guide to Managing Knowledge. Boston, MA: Harvard Business School Press.

Wescott, G. (2002). Partnerships for capacity building: community, governments and universities working together. Ocean Coast. Manag. 45, 549-571. doi: 10. 1016/S0964-5691(02)00086-8

Young, O. R., Osherenko, G., Ekstrom, J., Crowder, L. B., Ogden, J., Wilson, J. A., et al. (2007). Solving the crisis in ocean governance place-based management of marine ecosystems. Environment 49, 20-32. doi: 10.3200/ENVT.49. 4.20-33

Conflict of Interest: The authors declare that the research was conducted in the absence of any commercial or financial relationships that could be construed as a potential conflict of interest.

Copyright (c) 2020 Dalton, Skrobe, Bell, Kantner, Berndtson, Gerhardinger and Christie. This is an open-access article distributed under the terms of the Creative Commons Attribution License (CC BY). The use, distribution or reproduction in other forums is permitted, provided the original author(s) and the copyright owner(s) are credited and that the original publication in this journal is cited, in accordance with accepted academic practice. No use, distribution or reproduction is permitted which does not comply with these terms. 